\title{
Separate contributions of texture and grain size on the creep mechanisms in a fine grained magnesium alloy
}

\author{
J.A. del Valle and O. A. Ruano \\ Dept. of Physical Metallurgy, Centro Nacional de Investigaciones Metalúrgicas (CENIM), \\ CSIC, Avda. de Gregorio del Amo 8, 28040 Madrid, Spain
}

\section{Introduction}

Magnesium alloys have recently attracted significant interest due to their excellent specific properties that make them potentially suitable candidates for replacing heavier materials in some automobile parts. The limitations of Mg alloys reside basically in their cold forming properties and limited high temperature properties. Superplastic forming of $\mathrm{Mg}$ alloys is an alternative way of shaping these materials into complex geometries.

It is generally accepted that a micrometer grain size is needed to obtain a superplastic behavior. Therefore, several investigations have been focused on optimizing grain refinement processing routes. Particularly, severe plastic deformation (SPD) techniques such as equal channel angular pressing (ECAP) [1,2,3] and large strain hot rolling (LSHR) [4] are effective processes to achieve superplastic conditions.

The effect of refining the grain size is to enhance the grain boundary sliding (GBS) mechanism relative to slip creep. According to the literature, the mechanical behavior of metallic materials during creep at high temperatures is generally described by the following power law relation between the strain rate, $\dot{\varepsilon}$, and the stress, $\sigma,[5,6]$ :

$$
\dot{\varepsilon}=A\left(\frac{E b}{k T}\right) D\left(\frac{b}{d}\right)^{\mathrm{P}}\left(\frac{\sigma}{E}\right)^{\mathrm{n}}
$$

where $\mathrm{A}$ is a material constant, $\mathrm{E}$ is Young's modulus, $\mathrm{D}=\mathrm{D}_{0} \exp (-\mathrm{Q} / \mathrm{RT})$ is the appropriate 
diffusion coefficient, $\mathrm{Q}$ is the activation energy, $\mathrm{R}$ is the gas constant, $\mathrm{T}$ is the absolute temperature, $\mathrm{b}$ is the magnitude of the Burgers vector, $\mathrm{d}$ is the grain size, $\mathrm{n}$ is the stress exponent, and $\mathrm{p}$ is the grain size exponent.

When GBS dominates at low stresses, $\mathrm{n}=2$, $\mathrm{p}=2$ or 3 , and $\mathrm{Q}=\mathrm{Q}_{\mathrm{L}}$ (activation energy for lattice self-diffusion) or $\mathrm{Q}=\mathrm{Q}_{\mathrm{gb}}$ (activation energy for grain boundary diffusion). Low stress exponents characterize GBS and therefore good superplastic behavior.

There is some controversy about the interrelation between the texture and the GBS mechanism. Most studies focus on the influence of superplastic deformation, i.e. GBS, on the texture evolution during deformation [7]. It is generally accepted that GBS progressively removes the texture and that, at large strains, the texture is more random. On the other hand, few studies analyze the influence of texture on the GBS mechanism. Most of them were performed on hexagonal metals that exhibit anisotropic characteristics even at high temperatures: $\mathrm{Cd}[8], \mathrm{Zn}[9,10,11]$, $\mathrm{Ti}[12,13], \mathrm{Zr}[14]$ and $\mathrm{Mg}$ [15]. In general, the observed effects were attributed to an influence of crystallographic factors on GBS via their influence on the necessary accommodation, by slip, in zones near the grain boundaries [8]. Otherwise, it was supposed that the texture effect is connected with changes in the grain boundary structure claiming that high angle misorientations enhance grain boundary sliding [9]. In contrast, according to other authors, texture has a negligible effect on GBS [7,13,14].

On the other hand, at large strain rates, stress exponents larger than $n=5$ are usually found in magnesium alloys. Several specific mechanisms have been proposed in such situations, taking into account the measured activation energies, including diffusioncontrolled dislocation climb and cross-slip controlled slip creep. Irrespective of these mechanisms, no grain size dependence is expected in this stress range. However, in some hexagonal metals, Cd [8], Zn [16,], and Mg [15], texture effects have been found in this regime. 
Ideally, an investigation of the effects of grain size and texture on the stress-strain rate response needs the preparation of samples with one of these microstructure parameters fixed and a controlled variation of the other. Another requirement is that the programmed microstructures remain stable during the tensile test at high temperature since determination of the stress-strain rate data must be performed before substantial changes in the microstructure takes place.

One of the main difficulties is the proper evaluation of the flow stress due to the concurrent grain growth that occurs during a high temperature test. Our experience indicates that grain sizes below $10 \mu \mathrm{m}$ are, in the AZ and AM magnesium alloys, very unstable at temperatures higher than 473-523 K and low strain rates. Grain growth drives the flow stress up during the tensile test when GBS is the controlling mechanism. This is a consequence of its dependence on grain size, given in Eq.(1). Moreover, a transition between GBS and dislocation dominated flow could occur as grain size coarsens during the tensile test [17] leading to changes in the stress exponent. An additional difficulty arises in some alloys, as for Zn-22\%Al [9], where grain growth is strongly dependent on the texture of the samples, precluding the separation of texture and grain size effects.

In addition to grain growth, it is also known that the texture weakens under superplastic deformation. Therefore, the procedure of measuring the stresses, at a fixed strain level in the tensile test, for samples with the same initial grain size and texture, could lead to misleading results. This is because the evolution of the microstructures can differ depending on the conditions of temperature and strain rate.

These difficulties lead us to perform the present study on samples with more stable grain sizes, larger than $10 \mu \mathrm{m}$, and to use strain rate change tests to determine the stress exponents. Thus, structural changes during the measurements have been minimized.

Another problem concerns the sample production. In the first place, it is necessary to 
obtain samples with the same texture and different grain sizes. Using a severe plastic deformation processing, such as ECAP or severe rolling, it is possible to refine the grain size and successively to obtain samples with coarser grain sizes by means of controlled heat treatments. By this method, samples with practically the same texture but different grain size were obtained.

On the other hand, in order to investigate the texture effect, it is desirable to prepare samples with the same grain size but different textures. This was carried out using different processing routes. For example, solubilized cast samples have a nearly random texture while sharp textures are obtained by rolling and ECAP. However, it is very difficult to obtain, by means of thermal treatments, exactly the same grain size and simultaneously the same size distribution and morphology for two samples with different textures. We performed, therefore, a study of the grain size influence by determination of its exponent $p$ in Eq.(1). Furthermore, by the use of the compensated strain rate, $\dot{\varepsilon}(\mathrm{d} / \mathrm{b})^{\mathrm{p}}$, the grain size effect could be discounted. This allows a proper determination of the texture effect.

The aim of the present study is to investigate the creep behavior of AM60, a single phase Mg-Al alloy, in the states of solubilized cast material and processed by LSHR and ECAP plus annealing treatments to have different texture conditions and grain sizes. Special attention is given to the influence of microstructure on the mechanisms of slip creep and GBS in the high and low stress exponent regimes respectively. The knowledge of the microstructure influence on the plasticity mechanisms can obviously help to obtain the optimal processing conditions for superplastic applications.

\section{Experimental Procedure}

The AM60 alloy was provided by Noranda Magnesium in the form of as-cast slabs of 4 mm in thickness. The alloy composition is given in Table 1 . The cast alloys were solution 
heat treated (henceforth termed Cast+ST samples) at $723 \mathrm{~K}$ for 30 minutes and water quenched in order to obtain an equiaxed single-phase microstructure prior to processing.

The AM60 alloy was processed via two SPD routes, rolling and ECAP by route C, in order to obtain samples with different textures. The rolling process consisted of two successive rolling passes of, respectively, $10 \%$ and $70 \%$ thickness reduction at $673 \mathrm{~K}$. The equivalent Von Mises strain is 1.9. These samples are henceforth termed R-samples.

The ECAP processing of the AM60 alloy consisted of two passes in total, at $523 \mathrm{~K}$, using a square die of $12 \times 12 \mathrm{~mm}$, with an intersection angle of $\Phi=90^{\circ}$ and a plunger speed of $0.1 \mathrm{~mm} / \mathrm{s}$. In order to perform the ECAP process with slabs of $4 \mathrm{~mm}$ in thickness they were stacked as shown in Fig. 1. The reference coordinate system is also drawn in the figure. The die was heated in situ during the ECAP process and the temperature of the die was maintained stable at $523 \mathrm{~K}$. The ECAP process was carried out by route $\mathrm{C}$, the stack was rotated $180^{\circ}$ around the extrusion direction (ED) of the first pass. These samples are henceforth termed EC-samples

Subsequently, the processed AM60 samples were annealed in order to produce a coarsening of the grain size. The final grain sizes of the samples are in the range of 10-40 $\mu \mathrm{m}$. Larger grain sizes are difficult to obtain, using annealing treatments, because abnormal grain growth produces heterogeneous samples. The microstructures of the alloy in the different stages of processing were examined by optical microscopy (OM). Details on sample preparation are given elsewhere $[18,19,20]$.The grain size, $d$, was calculated from the mean intercept length using a 1.74 factor, measuring about 1500 grains per sample. The Saltykov method was used to estimate the spatial grain size distribution from the distribution of their sectional areas measured from metallographic samples [21, 22].

X-ray texture measurements were carried out by means of the Schulz reflection method using a Siemens diffractometer furnished with a D5000 goniometer and an open Eulerian 
cradle. The X-radiation was $\beta$-filtered $\mathrm{CuK} \alpha$.

Dog-bone tensile samples of $15 \mathrm{~mm}$ gage length and a radius of $3 \mathrm{~mm}$ were machined out of the Cast+ST, R and EC slabs with the tensile axis parallel to RD and ED, respectively. Tensile tests were performed in a screw driven Servosis testing machine equipped with a parabolic furnace at temperatures in the range 423 to $723 \mathrm{~K}\left(0.5\right.$ to $0.8 \mathrm{~T}_{\mathrm{m}}$ where $\mathrm{T}_{\mathrm{m}}$ is the absolute melting temperature). The testing machine conducts an automatic adjustment of crosshead speed by compensation of the gauge length increase to maintain constant true strain rates.

An example of the stress-strain rate data determination by means of strain rate change tests is given in Fig. 2 for an EC sample with $d=22.5 \mu \mathrm{m}$ and a R sample with $\mathrm{d}=20.3 \mu \mathrm{m}$. The initial strain rate used in these tests was $10^{-3} \mathrm{~s}^{-1}$. A first strain rate jump down to $1.8 \times 10^{-5}$ $\mathrm{s}^{-1}$ is performed at a small strain of about $\varepsilon=0.05$ once the maximum load is reached. Subsequently, the strain rate is increased in successive jumps until the initial strain rate is reached at a strain of about 0.10 . In this way, the first strain rate change occurs before any noticeable dynamic recrystallization takes place, and the time spent at the lower strain rates is relatively short before any noticeable grain growth occurs. For obtaining the stresses at strain rates higher than $10^{-3} \mathrm{~s}^{-1}$, the tests were initiated at the same strain rate of $10^{-3} \mathrm{~s}^{-1}$ but jumps up to the higher strain rates were performed. In fact, the grain size was measured at different stages of the test by removing the load and quenching the samples. It was verified that no noticeable changes in grain size occurred during the low strain rates. Later, dynamic recrystallization at the higher strain rates is minimized and only some waviness of the grain boundaries was observed indicating the beginning of dynamic recrystallization [23].

It is worth noting that the initial stress level is recovered at the end of the strain rate jumps as it is shown in Fig. 2, thus indicating that the microstructure holds during the strain rate changes. The condition of constant structure is not fulfilled for samples with grain sizes 
lower than about $10 \mu \mathrm{m}$ at the temperatures considered in this work. Therefore, we present only data for larger grain sizes.

\section{Results}

\subsection{Microstructure characterization}

Fig. 3a shows the microstructure of the Cast+ST AM60 alloy. The mean grain size is $17.9 \mu \mathrm{m}$. Fig. 3b shows the measured (0002) pole figure for this sample. As can be seen, no significant texture components can be detected; the crystallites are randomly oriented, as usual in Mg cast alloys. Grain boundary misorientation is commonly described by means of the misorientation angle, which has a characteristic probability distribution depending on the texture of the sample [24]. Fig. 3c shows the distribution corresponding to a random textured hcp polycrystals that should correspond to the Cast+ST AM60 alloy.

A refined microstructure is developed during the LSHR process, which is formed by a relatively low fraction of large grains of about $7 \mu \mathrm{m}$ embedded in a matrix of small grains of about $2 \mu \mathrm{m}$ in size. The LSHR processing of the AM60 alloy was analyzed in detail in a previous paper [18]. Basal planes parallel to the rolling plane with a slight spread give the texture developed. Figs. $4 \mathrm{a}$ and $4 \mathrm{~b}$ summarize the textures obtained after rolling the Cast $+\mathrm{ST}$ AM60 alloy and after rolling plus an annealing treatment of 30 minutes at $723 \mathrm{~K}$, respectively. The grain size after this treatment was $d=17 \mu \mathrm{m}$. As can be seen, after the annealing treatments, the texture remains constant with only a slight spread. In previous works $[25,26]$, the distribution of misorientation angles has been measured for the AZ31 alloy with a rolling process similar to that applied here to the AM60 alloy, Fig. 3c. Moreover, the AZ31 alloy develops the same basal texture as the AM60 alloy. As can be seen, a lower amount of high angle boundaries is expected in these samples in comparison with the Cast+ST samples. Similar results are expected for the AM60 rolled samples. 
The texture obtained during ECAP of the AM60 alloy is shown in Fig. 4c. For route C, the (0002) pole figure reveals the formation of a maximum located at $45^{\circ}$ from the ED direction towards the TD direction indicating that the basal planes rotate to a position parallel to the shear direction during ECAP. As it is known, the slip planes operative in one pass are well oriented for the continuation of the strain in the next ECAP pass by route C. Thus, their orientation remains stable. It was found that, regardless of the SPD route used, the annealing treatments hardly change these textures.

It can be noted that the textures of EC and R samples practically consist in an alignment of the c-axis in one particular direction with respect to the rolling or extrusion direction. In fact, the EC texture can be obtained by a rigid rotation of the rolling texture. Therefore, its difference is the orientation of the basal planes of the grains with respect to the tensile axis, which is in the rolling-extrusion direction.

In a previous work [20], the microstructure of the AM60 alloy after two ECAP passes by route $\mathrm{C}$ was shown. Significant grain refinement takes place. The microstructures observed after these two processing routes, ECAP-C and LSHR, are quite similar [20]. They consist of relatively large zones of fine grains of about 1 to $2 \mu \mathrm{m}$ with a few coarse grains of about $10 \mu \mathrm{m}$.

As mentioned in Section 2, in order to avoid problems related to the grain growth during the measurement of the stress-strain rate data, it is preferable to have a mean grain size larger than about $10 \mu \mathrm{m}$. Therefore, the mechanical data given in this paper refers always to processed and annealed samples. For brevity, these EC+annealing and R+annealing samples will be henceforth termed EC and R samples without the reference to the annealing. The mean grain size will be indicated in each case.

To describe the grain size distributions, the intercept length per class interval was calculated, $\mathrm{L}_{\mathrm{i}}=\mathrm{L}_{\text {class,i }} \mathrm{N}_{\mathrm{i}}$. Next, the percentage of intercept length per class interval was 
calculated as $\mathrm{L}_{\mathrm{i} \%}=100 \mathrm{~L}_{\mathrm{i}} / \mathrm{L}_{\mathrm{T}}$. In Fig. 5, histograms of $\mathrm{L}_{\mathrm{i} \%}$, are given for an EC, $\mathrm{R}$, and Cast $+\mathrm{ST}$ processed samples. The mean intercept length, $\overline{\mathrm{L}}$, is also shown. The duplex distribution is more pronounced in the case of rolled and annealed samples. On the contrary, the distribution of the Cast+ST samples shows a narrow distribution. The form of the respective distributions remained stable during grain growth induced by the annealing treatments. However, beyond 40-50 $\mu \mathrm{m}$ a considerable abnormal growth occurs in both, the rolled and ECAPed samples.

Taking into account that $\mathrm{L}_{\mathrm{i}}$ is proportional to the volume fraction of each class of grains, it seems that the grain size obtained from the mean intercept length underestimates slightly the grain size due to the relatively large volume fraction of the coarser grains. Fig. $5 \mathrm{~d}$ shows the number of grains per $\mathrm{mm}^{3}, \mathrm{~N}_{\mathrm{v}, \mathrm{i}}$, as a function of size $\mathrm{d}_{\mathrm{i}}$, obtained using the Saltykov method for the same sample of Fig. 5a.

The grains obtained after the annealing treatments are equiaxed and free of precipitates because the annealing temperature is above the solubility line of the aluminum-magnesium phase diagram. Moreover, we confirmed that the shape of the grain size distribution remains approximately constant under the annealing treatments performed.

\subsection{Mechanical behavior}

The graphs of Fig. 6 are plots of the strain rate against the Young modulus compensated stress for the AM60 Cast+ST, R and EC samples with different grain sizes. The data shown were obtained from strain rate change tests described earlier. As usual in magnesium alloys [27, 28], the creep behavior can be described by a power law, Eq.(1), where two stress exponent regimes can be distinguished. In the low stress-exponent regime, at low strain rates and temperatures above $573 \mathrm{~K}, \mathrm{n}$ is close to two. Below this temperature, increasing stress exponents are obtained at 523 and $473 \mathrm{~K}$, and the low exponent regime progressively 
disappears.

In contrast, in the high stress-exponent regime, the stress exponents vary between 3 and 12 for decreasing temperature from 723 to $423 \mathrm{~K}$. In this regime, the stress depends strongly on the previous processing at the lower temperatures 473, 523 and $573 \mathrm{~K}$. Noticeable grain size dependence becomes evident with increasing temperature. Some precipitation may occur at testing temperatures lower than $573 \mathrm{~K}$. However, it was found that the influence on the creep properties was negligible. The grain size and texture effects on both regimes will be analyzed in the discussion section.

\section{Discussion}

\subsection{Low stress exponent regime $(n \approx 2)$}

The low stress exponent regime $(n \approx 2)$, shown in Fig. 6 , includes strain rates lower than about $2 \times 10^{-4} \mathrm{~s}^{-1}$, at $573 \mathrm{~K}$, and lower than about $10^{-3} \mathrm{~s}^{-1}$, at $648 \mathrm{~K}$. This regime is present irrespective of the texture of the samples analyzed. In addition, the measured values of $n$ are close to the value corresponding to the GBS mechanism [5].

According to the literature, a strong grain size effect is expected for creep controlled by GBS through the influence of the term (b/d) $)^{\mathrm{p}}$ in equation (1). In Fig. 7, $\sigma / \mathrm{E}$ is plotted as a function of the grain size at a fixed strain rate of $5 \times 10^{-5} \mathrm{~s}^{-1}$. As it is shown, the grain size exponent is close to $\mathrm{p}=2.1$ for both temperatures, 573 and $648 \mathrm{~K}$. Most of the data correspond to R-samples. Data from EC and Cast-ST samples also follow the same trend.

The representation by means of the compensated strain rate, $\dot{\varepsilon}(d / b)^{2.1}$, for the samples with different textures, makes feasible to inquire on the texture effect, isolated from the strong grain size effect. As can be seen in Fig. 8, the low stress data for 573 and $648 \mathrm{~K}$ converges on the same curve irrespectively of the orientation of the basal planes ( $\mathrm{R}$ against EC samples) or the misorientation distribution ( $\mathrm{R}$ against cast-ST samples). At $523 \mathrm{~K}$ the scatter is high, 
which is attributed to the absence of pure GBS as the controlling deformation mechanism. This is shown by the increasing values of the stress exponents observed, 2.5 to 4 . It is probable that slip creep plays a noticeable role below $573 \mathrm{~K}$. For this reason, the grain size dependence changes and the correction of the strain rate by the factor $(\mathrm{b} / \mathrm{d})^{\mathrm{p}}$ becomes useless.

Finally, the activation energy can be calculated from the data of Fig. 8. This is done in Fig. 9 where the stress is plotted against $\mathrm{T}^{-1}$ in a semilogaritmic representation for $\dot{\varepsilon}(\mathrm{d} / \mathrm{b})^{2.1}=$ $10^{5} \mathrm{~s}^{-1}$. Fig. 9 shows that the data can be fitted with a straight line; using an average stress exponent of 1.96, the obtained activation energy was $91 \pm 2 \mathrm{~kJ} / \mathrm{mol}$. This value matches the activation energy for grain boundary diffusion of $\mathrm{Mg}\left(\mathrm{Q}_{\mathrm{gb}}=92 \mathrm{~kJ} / \mathrm{mol}\right)$.

Summarizing, at low strain rates, the stress and grain size exponents and the activation energy correspond to the GBS mechanism [5]. In addition, once the grain size effect is appropriately compensated, neither a noticeable influence of the orientation of the basal planes with respect to the tensile axis nor an influence arising from differences on the misorientation distribution can be detected.

It is interesting to make a comparative analysis of previous results in hcp metals with those given in this work. Compression samples of extruded Cd ( $d=16 \mu \mathrm{m})$ cut in the extrusion direction and in the transverse direction were analyzed by Hsu et al. [8], the latter samples have the basal planes better oriented for basal slip. The flow stress was measured at a fixed strain of $7.5 \%$ for strain rate and temperature ranges of $1.4 \times 10^{-4}$ to $3.5 \times 10^{.2} \mathrm{~s}^{-1}$ and 300 to $533 \mathrm{~K}$ respectively. In Fig. 10 their data are compared with ours in a diffusion compensated strain rate vs. modulus compensated stress plot. The activation energy measured by Hsu et al, in the $\mathrm{n} \approx 2$ region corresponds to that for grain boundary diffusion. Due to the differences between longitudinal and transverse samples these authors conclude that there is a noticeable texture effect on the GBS, in the low stress exponent regime.

However, a close inspection of the transverse and longitudinal curves shows a tendency 
to converge at the lower strain rates. Moreover, the slope of the data corresponding to transverse samples shows a stress exponent closer to 3 than to 2. This probably indicates a contribution of dislocation slip in the transverse samples, which have the basal planes better oriented for slip. As it will be shown later, there is a strong influence of texture on slip dominated creep. Therefore, the Cd data may indicate that, at low strain rates, there is a transition region between slip (which depends on texture) to GBS dominated creep. This transition occurs at higher $\sigma / E$ values in the samples with the basal planes unfavorable oriented for basal slip. Our data, shown in Fig. 10, reveals a similar trend; however, the transition occurs at higher $\sigma / \mathrm{E}$ values. This figure shows that, in the $\mathrm{n}=2$ region, the texture effect vanishes for both EC and R samples.

Recently, Watanabe et al [15], carried out a compilation of data from Mg samples with different textures and grain sizes. However, due to the grain size scattering, these authors were not able to extract a concrete conclusion about the influence of texture on the GBS mechanism.

A considerable number of reports on the texture effect come from the works of Kaibyshev et al. [9, 10, 12] on the Zn-22\%Al alloy, and the VT6 titanium alloy [11]. Both alloys have a eutectoid microstructure. These authors found that a favorable texture leads to a decrease in flow stress, an increase in plasticity, and a shift of the optimum strain rate region (low stress exponent) to higher strain rates. The texture effect increases at lower temperatures or higher strain rates and the authors claim that this effect is connected with a change in grainboundary structure.

Padmanabhan and Lücke [7] criticize the experimental method used by Kaibyshev et al. to obtain samples with identical grain sizes and simultaneously different textures using various rolling schedules. They attribute the reported effects to the elongation of the grains in the rolling direction and to changes in grain size between different textured samples during 
deformation. In fact, Fig. 6 of Ref. [9] shows that the grain growth, during the test, depends strongly on the initial texture precluding the proper determination of strain rate sensitivities at equal grain size.

In addition to the arguments of Padmanabhan and Lücke, we would like to point out other factors, which can be responsible of the effects reported by Kaibyshev et al. In the first place there is evidence of a considerable contribution of dislocation slip during superplastic deformation of the Zn-22\%Al alloy [29]. Therefore, if deformation occurs with contributions of two deformation mechanism it could indicate that the slip contribution depends on texture, or that the relative contributions of each mechanism change when the texture is altered. Moreover, if the data is taken over a transition zone between slip and GBS, it is possible to find some texture effects as discussed for Cd. Secondly, it must be considered that these two materials, Zn-22\%Al and the VT6 alloy, are two phase eutectoids with a duplex microstructure. There is considerable evidence that in both alloys the GBS depends on the type of interfaces involved [30,31]. Thus, in order to evaluate properly the texture effect it is not enough to prepare samples with different textures and the same grain size. It is also necessary to have the same fraction of boundaries of each type. It is pointed out that in these reports of the texture effect no information about the grain size distributions is given. Moreover, as it is shown by Ghosh and Raj [32], variations of the grain size distribution can lead to misleading effects, such as the appearance of a maximum in the plot of the sensitivity index m against the strain rate and an apparent approach toward a threshold stress at lower strain rates. This effect could be erroneously attributed to the influence of texture if samples with equal mean grain size but different grain size distributions are analyzed.

\subsection{High stress exponent regime $(n>3)$}

Regarding the high stress exponent regime $(\mathrm{n}>3$ ) observed in this work, an analysis 
can be made concerning the texture and grain size effects. In the following, we attempt to isolate these effects.

\subsubsection{Texture effect}

As shown in Fig. 6a-c, the flow stress in the high stress regime depends on the orientation of the basal planes with respect to the tensile axis, at the temperatures 473,523 and $573 \mathrm{~K}$. For instance, at $473 \mathrm{~K}$ and grain sizes in the range 18-20 $\mu \mathrm{m}$, the R-samples show stresses that are 30\% larger than EC-samples while Cast+ST-samples show stresses that are 10\% larger than EC-samples. However, as can be seen in Fig. $6 \mathrm{~d}$ at $648 \mathrm{~K}$, the data for Rsamples $(\mathrm{d}=18.7 \mu \mathrm{m})$ and EC samples $(\mathrm{d}=19.5 \mu \mathrm{m})$ coincide. This allows us to conclude that the texture effect disappears when the temperature is increased from 573 to $648 \mathrm{~K}$. It is also noted that the lower stresses are measured for EC samples with the basal planes close to the ideal orientation ( $45^{\circ}$ to the tensile axis). In such condition, the Schmid factor for basal slip is expected to be about its maximum value, $\mathrm{m}_{\mathrm{s}, \mathrm{b}}=0.5$.

Regarding the texture effect at the lower temperatures, it has been found that data from samples with different textures can be put into coincidence by multiplication of the flow stress by a fixed factor, and the division of the strain rate by the same factor. Fig. 11a shows $\mathrm{R}$ and EC data where a conversion factor $\mathrm{m}_{\mathrm{r}}$ was applied to the EC data to put it into coincidence with the R data. This representation was performed for EC and R samples with similar grain sizes. Both sets of data, can be put together using a factor $\mathrm{m}_{\mathrm{r}}=1.25$ at $573 \mathrm{~K}$ and $\mathrm{m}_{\mathrm{r}}=1.35$ at 523 and $473 \mathrm{~K}$. Moreover, the same procedure can be used to put into coincidence the data of Cast-ST and R-samples. Fig. 10b shows that both sets of data can be put together using a factor $\mathrm{m}_{\mathrm{r}}$, which varies between 1.1 and 1.2 for decreasing temperature.

The simplest attempt to rationalize these results can be performed by modification of the power law equation to include the crystallographic orientation factor for basal slip. First, 
an expression for creep relating the basal resolved stresses, $\tau_{\mathrm{b}}$, and the shears strain rate, $\dot{\gamma}_{\mathrm{b}}$, can be written:

$\dot{\gamma}_{\mathrm{b}}=\mathrm{A}\left(\frac{\tau_{\mathrm{b}}}{\mathrm{E}}\right)^{\mathrm{n}}$

The measured macroscopic magnitudes $\sigma$ and $\dot{\varepsilon}$ can be related to $\tau_{\mathrm{b}}$, and $\dot{\gamma}_{\mathrm{b}}$, by the relations $\dot{\varepsilon}=\mathrm{m}_{\mathrm{s}, \mathrm{b}} \dot{\gamma}_{\mathrm{b}}, \sigma=\tau_{\mathrm{b}} / \mathrm{m}_{\mathrm{s}, \mathrm{b}}$ where $\mathrm{m}_{\mathrm{s}, \mathrm{b}}$ is the Schmid factor for basal slip, leading to:

$$
\frac{\dot{\varepsilon}}{\mathrm{m}_{\mathrm{s}, \mathrm{b}}}=\mathrm{A}\left(\frac{\sigma \mathrm{m}_{\mathrm{s}, \mathrm{b}}}{\mathrm{E}}\right)^{\mathrm{n}}
$$

Therefore, it is predicted that the data of samples with different $\mathrm{m}_{\mathrm{s}, \mathrm{b}}$ factors can be put into coincidence if the stresses and strain rates of one of the data sets is corrected by the ratio of Schmid factors. For instance, for the conversion from EC to R data, this factor is $\mathrm{m}_{\mathrm{r}}=$ $\left[\mathrm{m}_{\mathrm{s}, \mathrm{b}}(\mathrm{EC}) / \mathrm{m}_{\mathrm{s}, \mathrm{b}}(\mathrm{R})\right]$

The average orientation of the basal planes for basal slip on R-samples can be estimated taking into account the dispersion of the c-axis around the normal direction shown in Figs. 3ab. Since most of the grains have the c-axis at about $15^{\circ}-20^{\circ}$ from the normal direction, the angle $\varphi$ is near to $70^{\circ}-75^{\circ}$, and the Schmid factor is expected to be about $\mathrm{m}_{\mathrm{s}, \mathrm{b}}=0.33$. Therefore the correction factor is estimated as $\mathrm{m}_{\mathrm{r}}=\left[\mathrm{m}_{\mathrm{s}, \mathrm{b}}(\mathrm{EC}) / \mathrm{m}_{\mathrm{s}, \mathrm{b}}(\mathrm{R})\right] \approx(0.5 / 0.33)=1.5$.

In the case of random textured Cast+ST samples, the Schmid factor for basal slip takes an intermediate value between the ideal orientation of EC samples and the large disoriented R samples. Thus a value of $\mathrm{m}_{\mathrm{r}}$ in the range $1<\mathrm{m}_{\mathrm{r}}<1.5$ is expected in this case. The predicted value of the correction factor is slightly larger than the measured and depends on temperature. This can be attributed to multiple slip that operates in addition to single slip in the basal system as was considered in the estimation of $\mathrm{m}_{\mathrm{r}}$. In the case of rolled samples it is expected that, in a unfavorable orientation for basal slip, an increasing contribution of prismatic slip, and therefore multiple slip, is present leading to lower flow stresses and therefore to lower 
values of the conversion factor between EC and R data. It is worth nothing that the decreasing trend of $\mathrm{m}_{\mathrm{r}}$ with increasing temperature may also indicate the growing importance of multiple slip.

Regarding the data of the literature in hcp metals, the consensus is that there is a noticeable effect of texture on creep when dislocation slip controls deformation. As shown in the Hsu et al data on Cd [8], Fig. 10, these authors find a low stress for polycrystals with grains well oriented for basal slip. In pure Zinc, Edwards et al. [16] tested transversal and longitudinal samples (with respect to the extrusion direction) and found that longitudinal samples are 1.5-2 times stronger that transversal samples. Moreover, they also found that the stress exponents are insensitive to the texture of the samples. Other studies in $\mathrm{Zn}-22 \mathrm{Al}$ and $\mathrm{Ti}$ 6Al-4V alloys [9] and AZ31 alloy [15] show a similar trend.

In summary, the presence of a texture effect is a characteristic of hcp metals in the high stress exponent regime. This behavior can be explained by the changes in the orientation factor for basal slip.

\subsubsection{Grain size effect}

Fig. 6 shows a surprising influence of the grain size on flow stress and stress exponent at high strain rates for samples with the same processing, i.e. with the same texture. Finer grain sizes leads to lower stresses and lower stress exponents. Moreover, this grain size effect increases with increasing temperature. For R-samples at $473 \mathrm{~K}, \mathrm{n}=10$. At $523 \mathrm{~K}$ there is a clear grain size effect, and the stress exponent $n$ decreases from 9.8 to 6.8 for a decreasing grain size from 23.5 to $17 \mu \mathrm{m}$. At $573 \mathrm{~K}$ a similar trend is shown in Fig. 6c. A similar dependence of the flow stress with the grain size, at relatively high strain rates, has been also observed in rolled AZ31-O with $\mathrm{d}=17 \mu \mathrm{m}$ [17].

The minor grain size effect at $473 \mathrm{~K}$, Fig. 6a, in the zone of high stress exponents is 
consistent with the observed grain size effect on work hardening [20, 33]. In these studies, a decrease in work hardening with decreasing grain size was observed at room temperature. This decrease in work hardening could lead to a decrease in the steady state stress. The grain size effect was attributed to grain boundary sliding, and to an increasing contribution of multiple slip as grain size decreases [20]. However, the relatively large grain size effect observed at higher temperatures, Fig. 6 for 523 to $648 \mathrm{~K}$, cannot be explained by the conventional theories of slip creep.

Summarizing, a grain size effect at high strain rates is present. This effect increases with increasing temperature and consists of a gradual decrease in the stress exponent to values close to 3. This evidence could be an indication that GBS may be contributing to deformation, since it predicts a grain size dependence of the flow stress.

Therefore, it can be assumed that a superposition of creep mechanisms (one of which is GBS and the other a slip creep mechanism) is responsible for our findings. In general, this kind of superposition arises in a transition zone between the two deformation mechanisms, in the stress interval where both mechanisms give strain rates of the same order. If one of the mechanisms is grain size dependent, as occurs with GBS, a transition zone is expected as the stress increases, with a decreasing influence of the grain size as the second mechanism starts to prevail. This transition zone extends over a narrow range of strain rates for a monodisperse grain size distribution. However, a broad grain size distribution may produce an extension of this transition over a wide range of strain rates. This is because the material behaves as a composite with the smaller grains contributing to deformation by the GBS mechanism and the larger grains by slip.

In the following, an attempt to model of these effects is made. We considered a modification of a model proposed by Ghosh and Raj [32] regarding the relative contribution of both mechanisms, slip and GBS, to deformation. In this model, it is assumed that each 
grain, of diameter $\mathrm{d}_{\mathrm{i}}$, deforms at the imposed macroscopic strain rate, $\varepsilon_{\mathrm{i}}=\dot{\varepsilon}$. On the other hand, the stress supported by these grains, $\sigma_{i}$, contributes to the overall stress weighted with their volume fraction, as in a composite material. Furthermore, the stress $\sigma_{i}$ may be related to the strain rate according to the addition of power laws:

$\dot{\varepsilon}=\mathrm{k}_{1}\left(\frac{\mathrm{b}}{\mathrm{d}_{\mathrm{i}}}\right)^{2}\left(\frac{\sigma_{\mathrm{i}}}{\mathrm{E}}\right)^{1.85} \mathrm{e}^{-\mathrm{Q}_{\mathrm{gb}} / \mathrm{RT}}+\mathrm{k}_{2}\left(\frac{\sigma_{\mathrm{i}}}{\mathrm{E}}\right)^{9} \mathbf{e}^{-\mathrm{Q}_{\mathrm{L}} / \mathrm{RT}}$

where the creep laws have parameters to be determined in both the low and high stress exponent regimes for R-samples. The activation energies used in the modeling procedure were $\mathrm{Q}_{\mathrm{gb}}=92 \mathrm{KJ} / \mathrm{mol}$ and $\mathrm{Q}_{\mathrm{L}}=135 \mathrm{KJ} / \mathrm{mol}$. The first activation energy has been obtained in this work for the GBS mechanism, and the second activation energy is that for lattice selfdiffusion for $\mathrm{Mg}$, and it is a tentative value. The parameters $\mathrm{k}_{1}$ and $\mathrm{k}_{2}$ are constants to be determined by fitting the data.

It is stressed that the purpose of this model is to show that the grain size effects, and the behavior of the stress exponents, could be explained by considering the contribution of GBS. Therefore it is out of the scope of the present work to perform a detailed analysis of the slip creep mechanism in Eq.(4) which is only considered as a high stress exponent mechanism that occurs at high strain rates and large grain sizes. Thus, a stress exponent of 9 , for the slip mechanism, is assumed because it corresponds to the behavior observed at $473 \mathrm{~K}$. Other values may be used without a drastic change of the general trend of the modeling. Additional information about the slip creep mechanism could be obtained by testing large grained materials, thus avoiding the GBS contribution.

Returning to the model, the macroscopic stress is given by the addition of the individual contributions weighted by the respective volume fractions:

$\sigma=\sum_{i} f_{i} \sigma_{i}$

where $f_{i}$ denotes the volume fraction of grains having diameter $d_{i}$. From the log-normal 
distribution of the number of particles per $\mathrm{mm}^{3}$ for $\mathrm{d}=20.3 \mu \mathrm{m}$, Fig. $5 \mathrm{~d}$, these volume fractions may be derived through the expressions:

$$
f_{i}=\frac{N_{v, i} V_{i}}{\sum_{i} N_{v, i} V_{i}}=\frac{N_{v, i} d_{i}^{3}}{\sum_{i} N_{v, i} d_{i}^{3}}
$$

The procedure to obtain a curve $(\dot{\varepsilon}, \sigma)$ is as follows: first for a given input value of $\dot{\varepsilon}$, the stress $\sigma_{i}$ is computed for each grain size $d_{i}$, using Eq.(4). Secondly, the total flow stress $\sigma$ is calculated with Eq.(5) using the volume fraction obtained with Eq.(6).

Furthermore, the parameters $\mathrm{k}_{1}$ and $\mathrm{k}_{2}$ were determined fitting the data of Fig. 12, for $573 \mathrm{~K}$ and $\mathrm{d}=20.3 \mu \mathrm{m}$. These parameters are $\mathrm{k}_{1}=5.4 \times 10^{19} \mathrm{~s}^{-1}$ and $\mathrm{k}_{2}=3.5 \times 10^{34} \mathrm{~s}^{-1}$. With these values fixed, a set of curves is obtained as continuous lines in Fig. 12 for the different temperatures. These curves are predictions, obviously, for $d=20.3 \mu \mathrm{m}$. Some experimental data for grain sizes close to $20 \mu \mathrm{m}$ are also shown in Fig. 12 for the various temperatures studied.

The agreement between the predicted curves and the general trend of the experimental results given in Fig. 12 is fairly good. The decrease in stress exponent with increasing temperature is clearly predicted. In Fig. 13a the stress exponents are given from both the fit of the experimental data and the derivatives of the modeled curves of Fig. 12 at $5 \times 10^{-3} \mathrm{~s}^{-1}$ for $\mathrm{d}$ $=20.3 \mu \mathrm{m}$. In the case of R-samples, the data on Fig. 13a have been grouped in two sets depending on the grain size. The stress exponent obtained from the experimental data have considerable scatter because the limited amount of experimental data at high strain rates. These measured stress exponents could be somewhat different from those given in Fig. 6, which were calculated by fitting in a broader range of strain rates.

Moreover, the grain size dependence at high strain rates is predicted. In Fig. 13b the data of R-samples with different grain sizes is shown. The influence of the grain size has been considered in the model scaling the experimental distribution for $d=20.3 \mu \mathrm{m}$ given in Fig. 5d 
for the samples with different grain sizes, i.e. by assuming that the reduced distribution holds constant. The model agrees fairly well with the experimental data. In the insert of Fig. 13b the stress exponent obtained from the calculated curves at the strain rate of $5 \times 10^{-3} \mathrm{~s}^{-1}$ is represented against the grain size. The dependence is clearly shown in the figure.

As shown in Fig. 12, the model underestimates slightly the strain rate at 648 and $723 \mathrm{~K}$ and overestimates slightly the strain rates at 473 and $523 \mathrm{~K}$. These deviations mainly arise from the method of estimating the volume fractions $\mathrm{f}_{\mathrm{i}}\left(\mathrm{d}_{\mathrm{i}}\right)$ and from the use of a slip creep equation with fixed values of the stress exponent and the activation energy.

By means of a modification of Eq.(4), it is possible also to obtain the curves for the other textures introducing the geometric factor $\left(\mathrm{m}_{\mathrm{r}}\right)^{\mathrm{n}+1}$ in the second term, without changing the parameters $\mathrm{k}_{1}$ and $\mathrm{k}_{2}$ obtained for R-samples. Thus, Eq.(4) may be rewritten:

$\dot{\varepsilon}=\mathrm{k}_{1}\left(\frac{\mathrm{b}}{\mathrm{d}_{\mathrm{i}}}\right)^{2}\left(\frac{\sigma_{\mathrm{i}}}{\mathrm{E}}\right)^{1.85} \mathrm{e}^{-\mathrm{Q}_{\mathrm{gb}} / \mathrm{RT}}+\mathrm{k}_{2}\left(\mathrm{~m}_{\mathrm{r}}\right)^{10}\left(\frac{\sigma_{\mathrm{i}}}{\mathrm{E}}\right)^{9} \mathrm{e}^{-\mathrm{Q}_{\mathrm{L}} / \mathrm{RT}}$

Fig. 12 shows the good agreement between the data for EC-samples and the prediction using the modification introduced in Eq.(7). The dashed line in Fig. 12 was obtained with $\mathrm{m}_{\mathrm{r}}$ $=1.25$ as given in Fig. 11a for $573 \mathrm{~K}$.

The election of $\mathrm{Q}_{\mathrm{L}}$ as the parameter controlling the temperature dependence gives a good description of the experimental data in Fig. 12 in the range of temperatures studied. However, a determination of the activation energy for deformation in the high strain rate regime is difficult to conduct since the lines that fit the experimental data at the various temperatures are not parallel (n is not constant).

It can be concluded that, in the high strain rate range, there is a monotonous decrease of the stress exponent with increasing temperature. Simultaneously, there is a decrease in the texture effect and an increase of the grain size effect with temperature. Most of these findings are congruently explained considering the contribution of GBS. A modification of the Ghosh and Raj model, which accounts for the grain size distribution, makes possible to fit the 
experimental data with a minimum of parameters.

\section{Summary and conclusions}

The influence of texture and grain size on the deformation mechanisms responsible for creep of an AM60 alloy has been investigated by means of strain rate change tests. The grain size range investigated was $10-40 \mu \mathrm{m}$. Samples with random texture and with the textures characteristic of ECAP and rolling processing were investigated. Two deformation regimes could be distinguished. In the low stress exponent regime, where the stress exponent is about 2, GBS is the controlling mechanism. In such situation, neither an effect on GBS of the orientation of the basal planes nor of the misorientation distribution is present.

On the other hand, in the high stress exponent regime the following results were obtained:

1) The texture effect decreases with increasing temperature. This effect consists in a decrease of the flow stress related to the orientation factor for basal slip without changes in the stress exponent. This decrease is attributed to the increasing activity of multiple slip and, at higher temperatures, to an increasing contribution of GBS.

2) Monotonous decrease of the stress exponent with increasing temperature was observed, with a broad variation from 10 to about 3 .

3) An increase of the grain size effect with increasing temperatures, beyond approximately $573 \mathrm{~K}$, was observed.

Items 2, 3 and partially 1 are congruently explained assuming that deformation occurs by a combination of GBS and slip, and considering a distribution of stresses based on the grain size distribution. Therefore, it is concluded that the deformation is controlled by two mechanisms, GBS and other mechanism with a high stress exponent, which is strongly related to basal slip. 


\section{Acknowledgments}

The authors are thankful to Dr. F. Carreño for kindly allowing the use of the ECAP equipment for this investigation. The authors acknowledge financial support from CICYT under program MAT 2003/1172. J.A.V. is thankful to the Spanish Ministry of Education and Science for a Ramon y Cajal contract.

\begin{tabular}{|c|c|c|c|c|}
\hline $\mathrm{Al}$ & $\mathrm{Zn}$ & $\mathrm{Mn}$ & $\mathrm{Si}$ & $\mathrm{Mg}$ \\
\hline $5.6-6.4$ & $0.2 \max$ & $0.26-0.5$ & $0.05 \max$ & Bal. \\
\hline
\end{tabular}

Table I: Composition of the magnesium AM60 alloy (in wt.\%) 


\section{FIGURES}
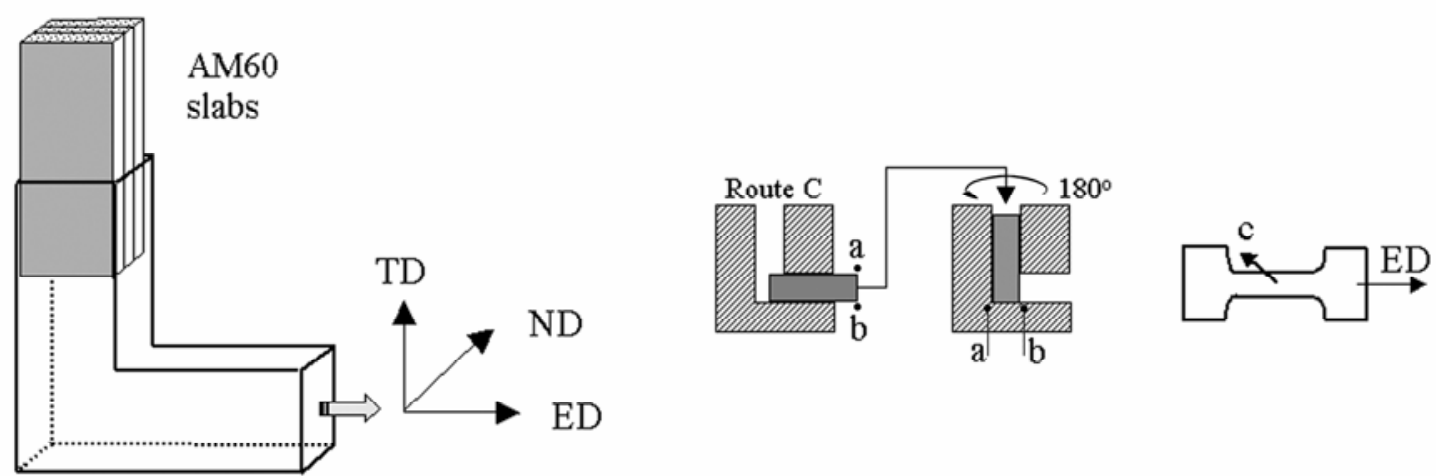

Fig.

1. Scheme of the ECAP processing of AM60 slabs by route C. The tensile samples were machined with the tensile axis parallel to the extrusion direction, ED. The approximate orientation of the c-axis is also depicted.

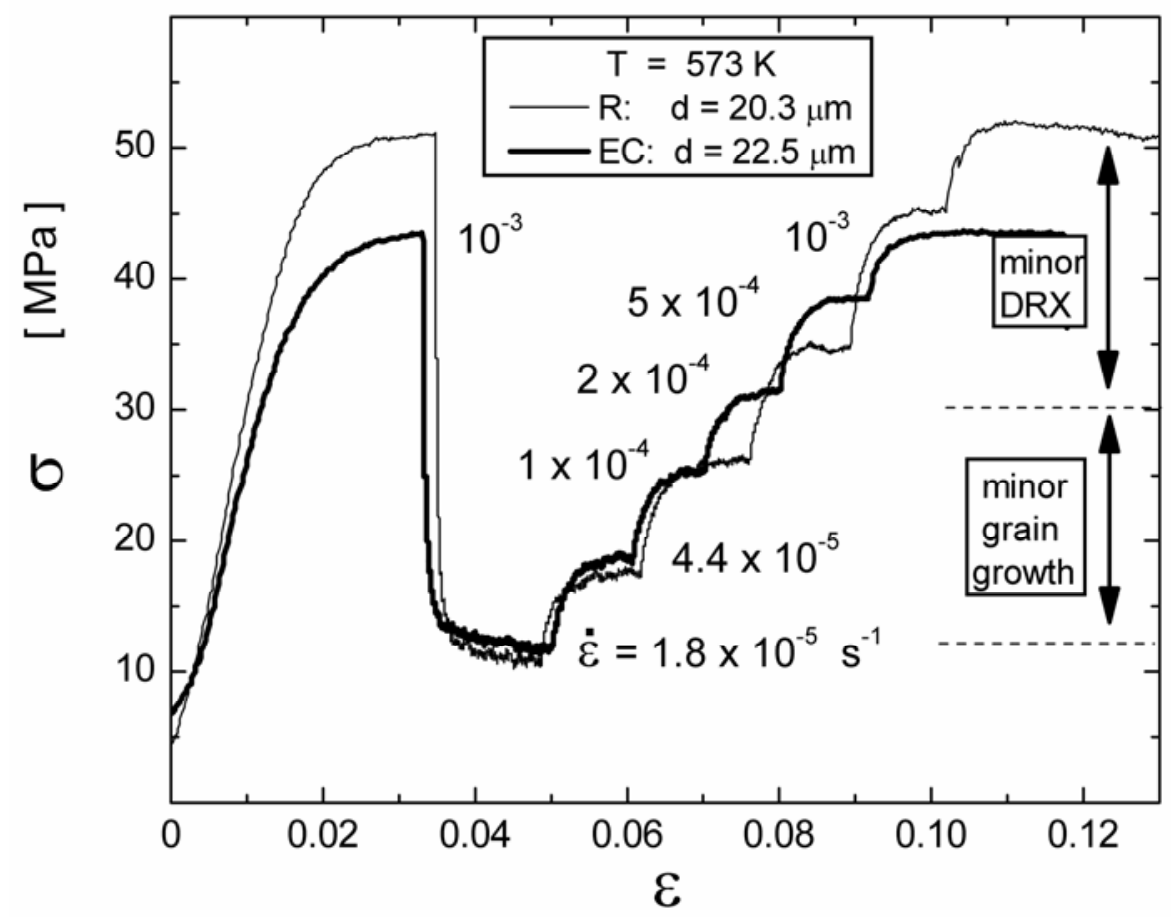

Fig. 2. Strain-rate-change test of two samples: An R-sample with a grain size $d=20.3 \mu \mathrm{m}$ and an EC-sample with $\mathrm{d}=22.5 \mu \mathrm{m}$. Zones with minor grain growth and minor dynamic recrystallization are indicated. 


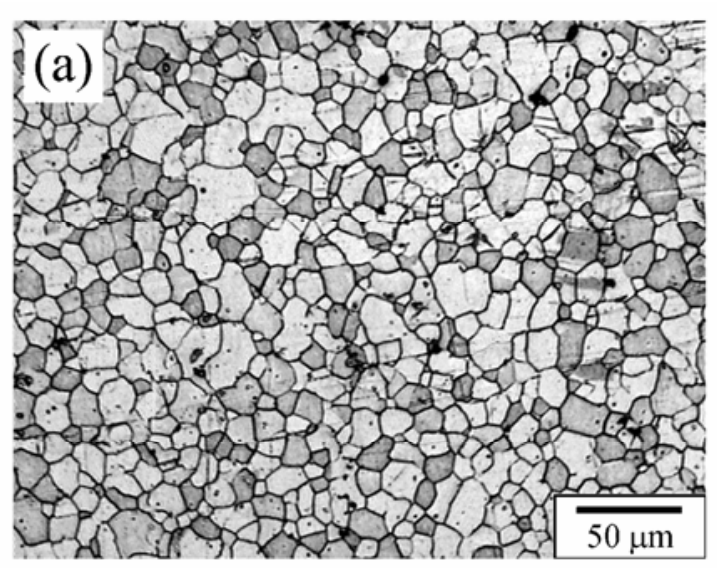

(b)
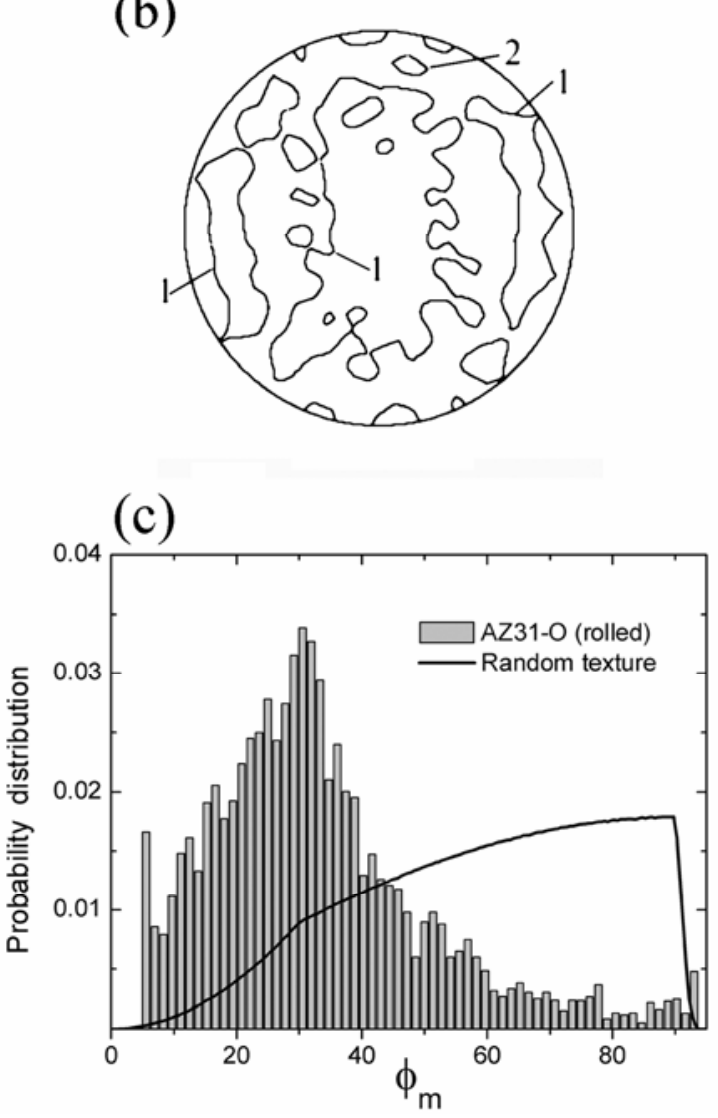

Fig. 3. (a) OM micrographs of solution treated (ST) AM60 alloy (b) Measured (0002) pole figure of the corresponding microstructure. The center of the pole figure corresponds to the normal of the cast slab. (c) Distribution of grain misorientations, $\phi_{\mathrm{m}}$, corresponding to a random texture [25], and distribution of the AZ31 alloy with a basal texture [25-26]. 

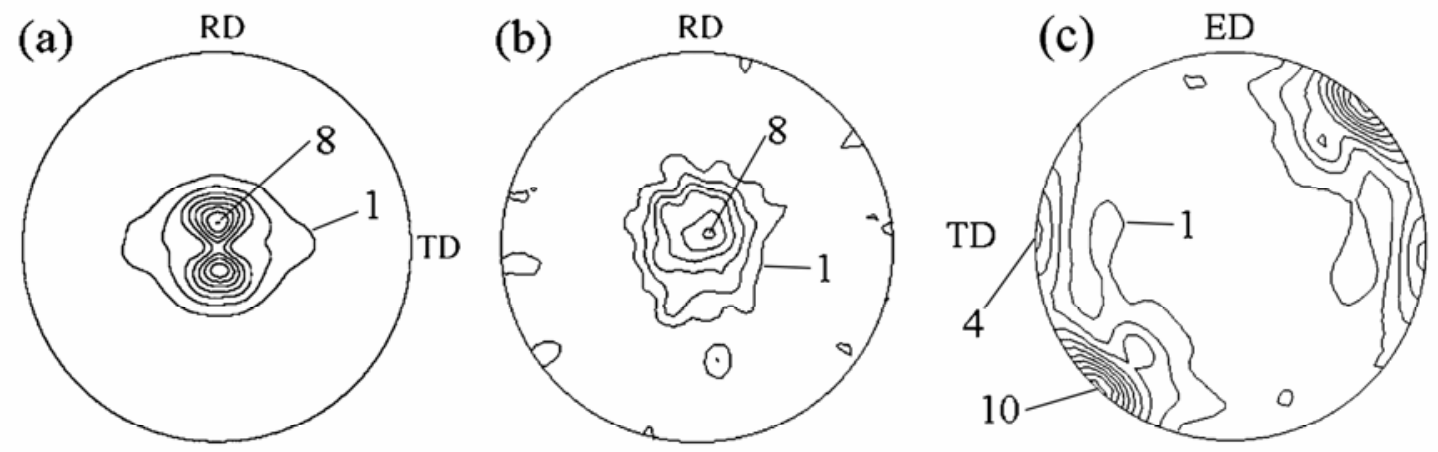

Fig. 4. Measured (0002) pole figures of the AM60 alloy (a) rolled, (b) rolled followed by a thermal treatment ST, (c) ECAPed with two passes by route C.
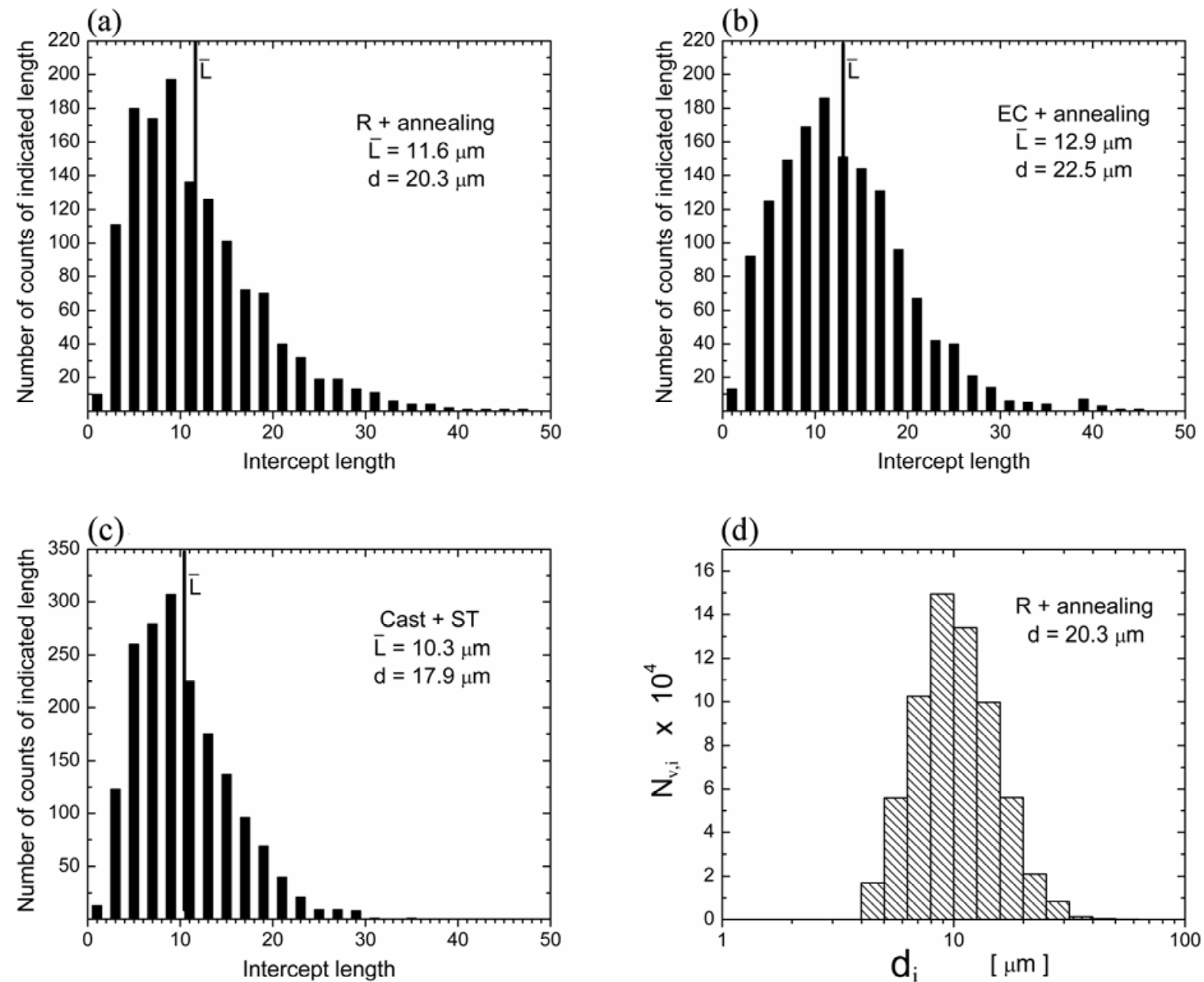

(d)

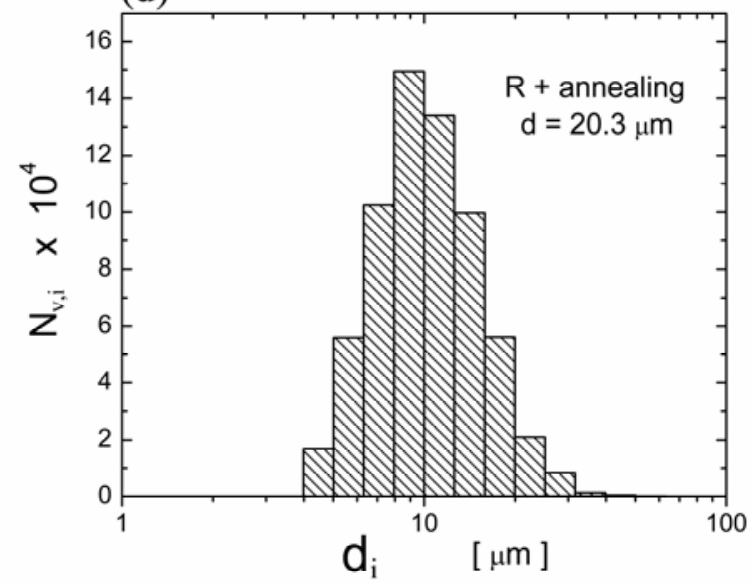

Fig. 5. Histograms showing the distribution of intercepted length for samples with different processing routes. (a) Rolled and annealed; (b) ECAPed and annealed; (c) Cast and ST; (d) Number of grains per $\mathrm{mm}^{3}$ obtained for the sample of Fig. 5a by the Saltikov method. 
(a)

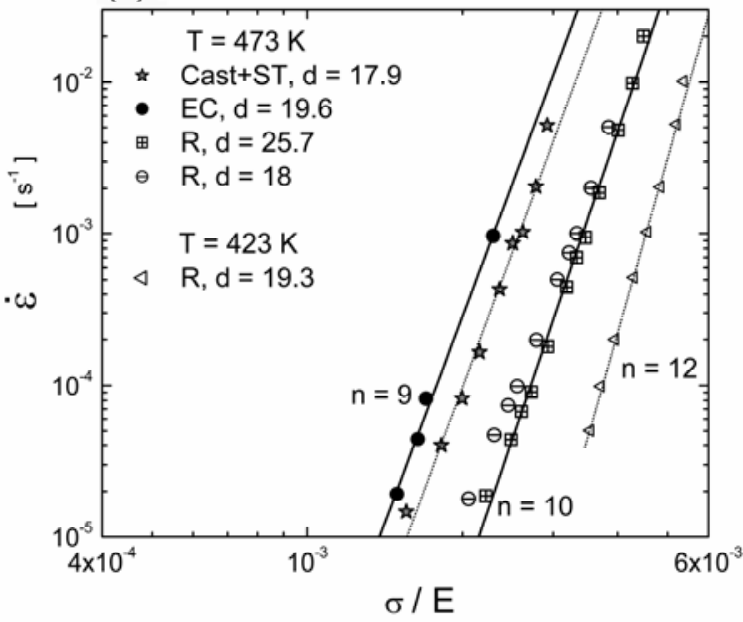

(c)

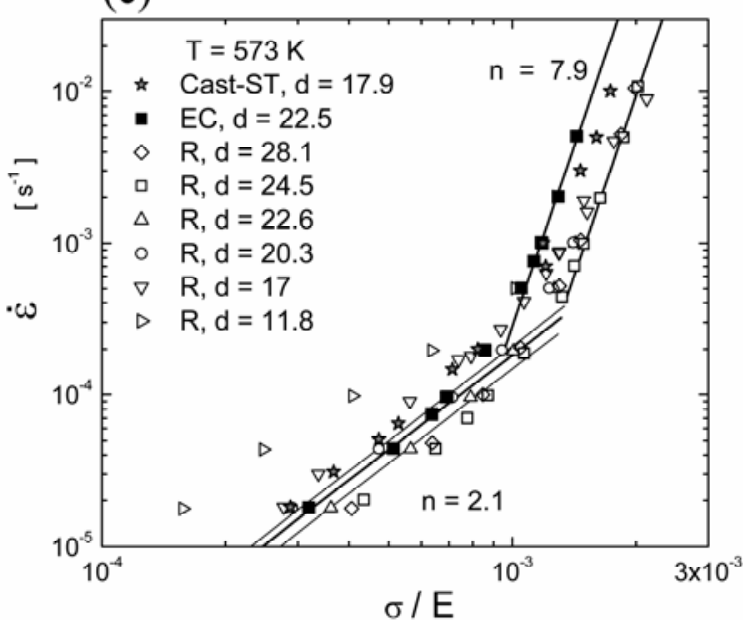

(b)

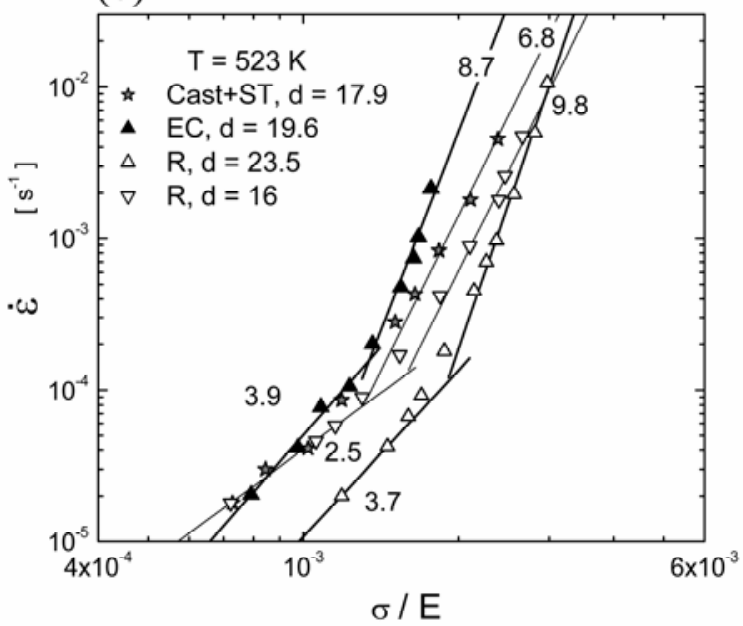

(d)

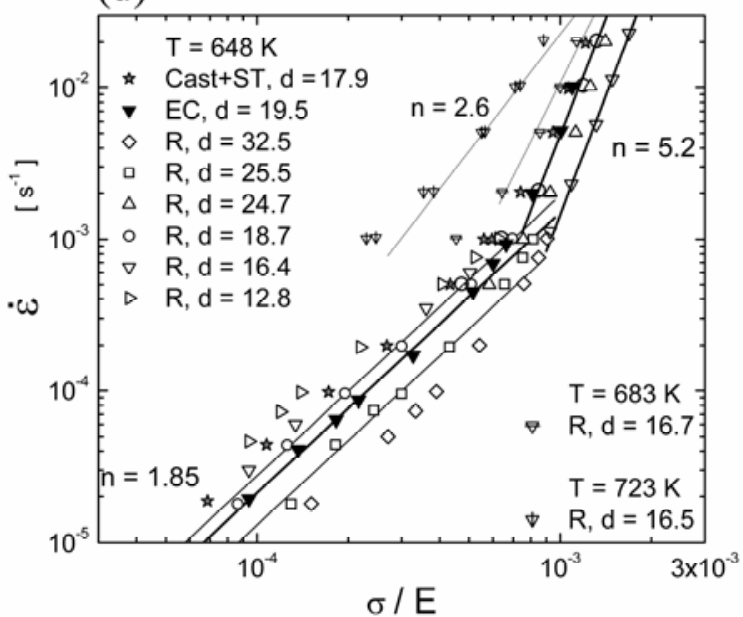

Fig. 6. The strain rate against the stress of Cast+ST, R and EC samples with different grain sizes tested at various temperatures. Grain sizes are given in microns.

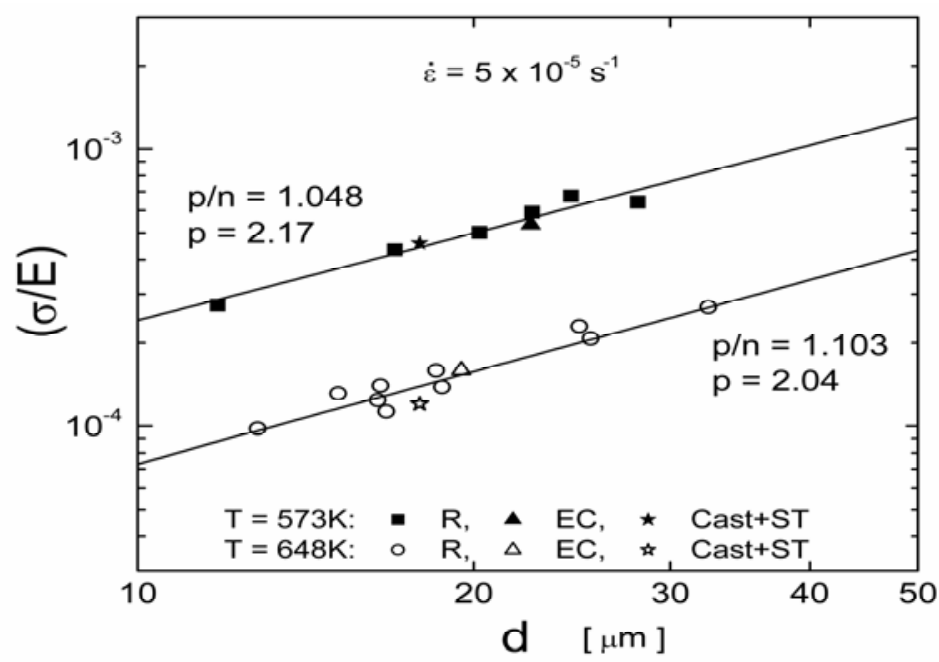

Fig. 7. The stress at 573 and $648 \mathrm{~K}$, measured at a strain rate of $5 \times 10^{-5} \mathrm{~s}^{-1}$, is plotted as a function of the grain size, for samples with different texture. 


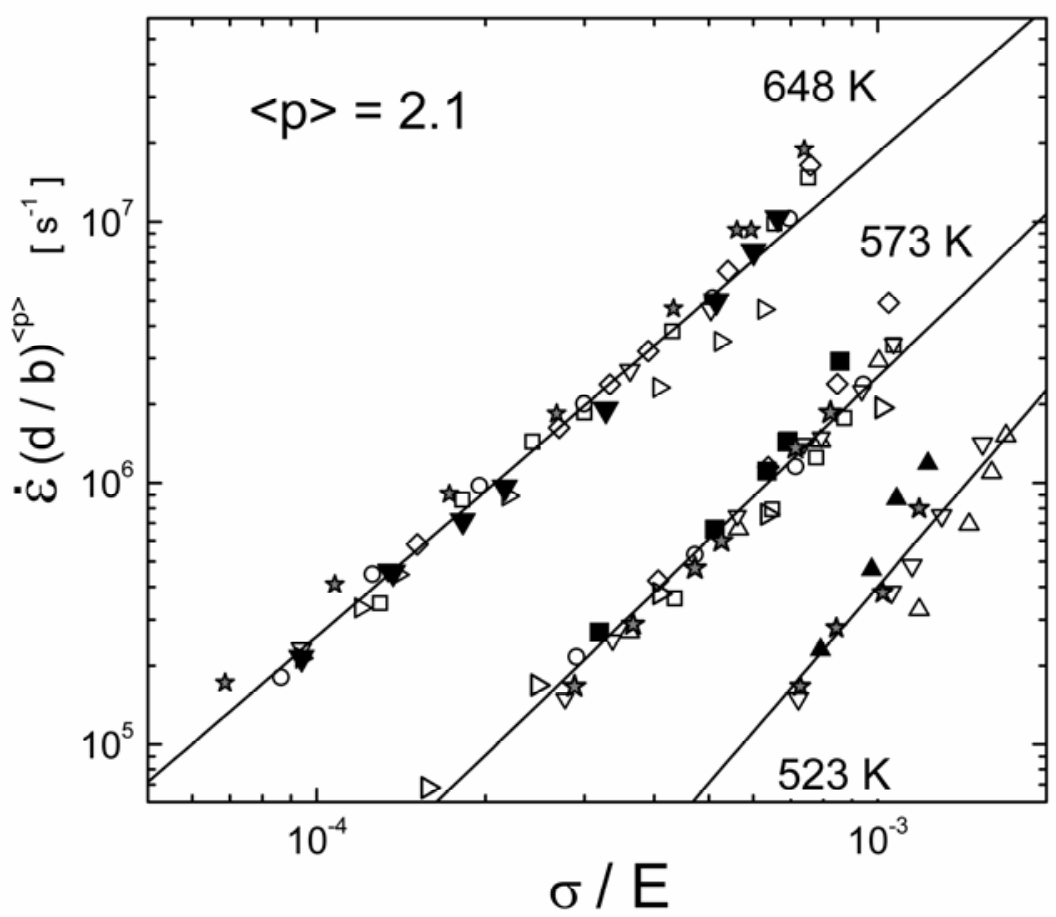

Fig. 8. Compensated strain rate, $\dot{\varepsilon}(\mathrm{d} / \mathrm{b})^{2.1}$ as a function of the stress, for samples with different textures. Symbols correspond to those of Fig. 6.

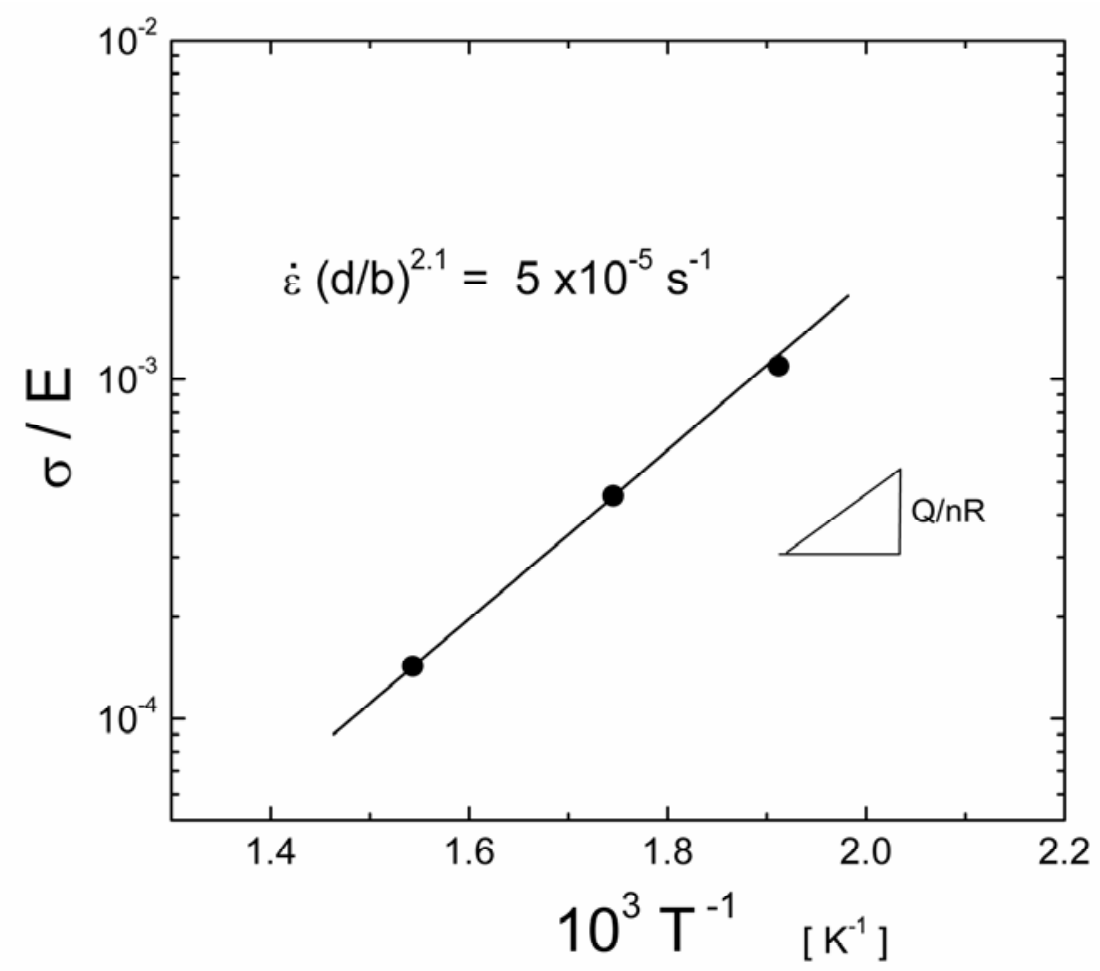

Fig 9. The stress is plotted against $\mathrm{T}^{-1}$ in a semilogarithmic representation at a given strain rate for determination of the activation energy. 


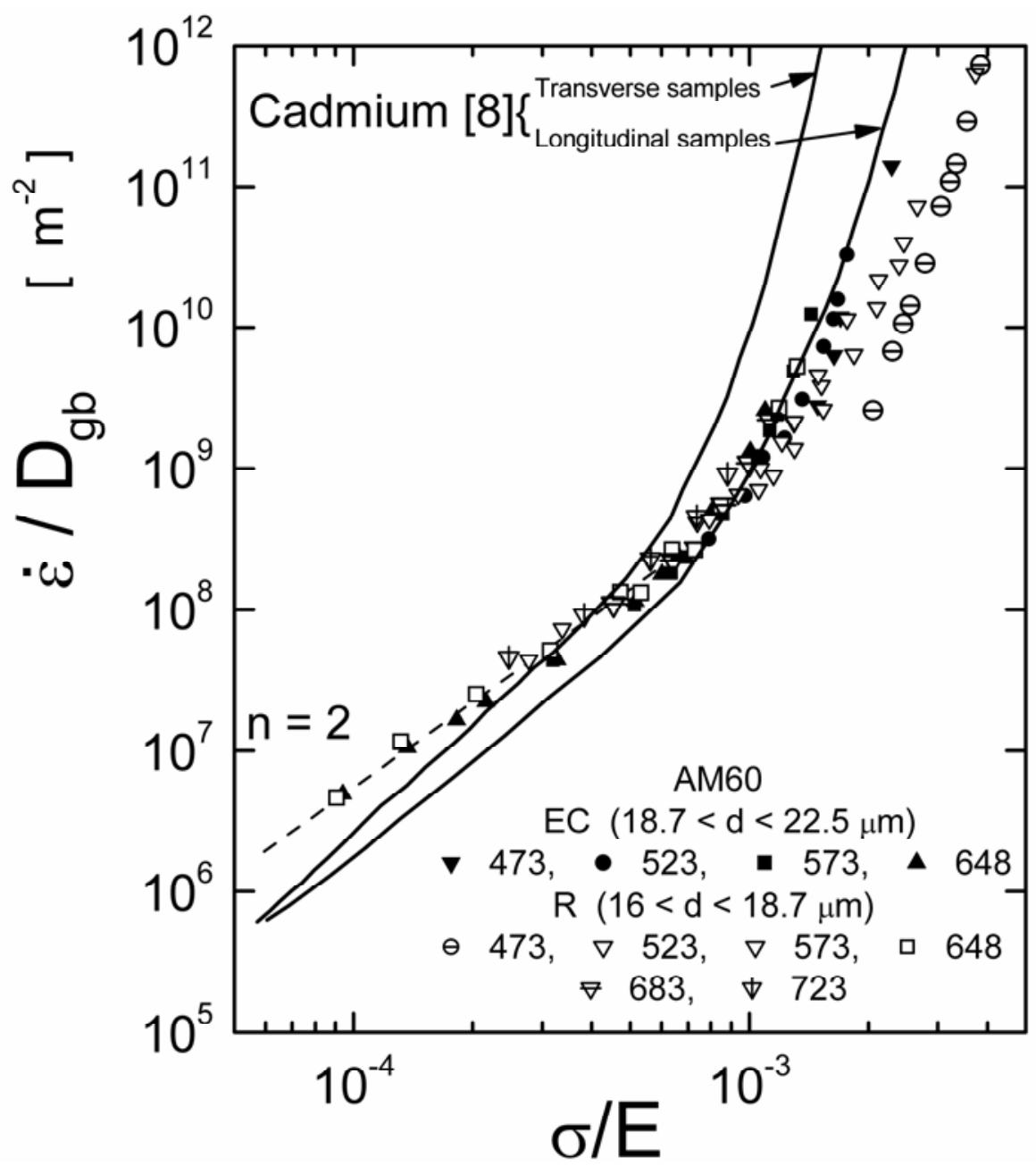

Fig 10. A comparison of our results against previous results of Hsu et al. in Cadmium [8]. 


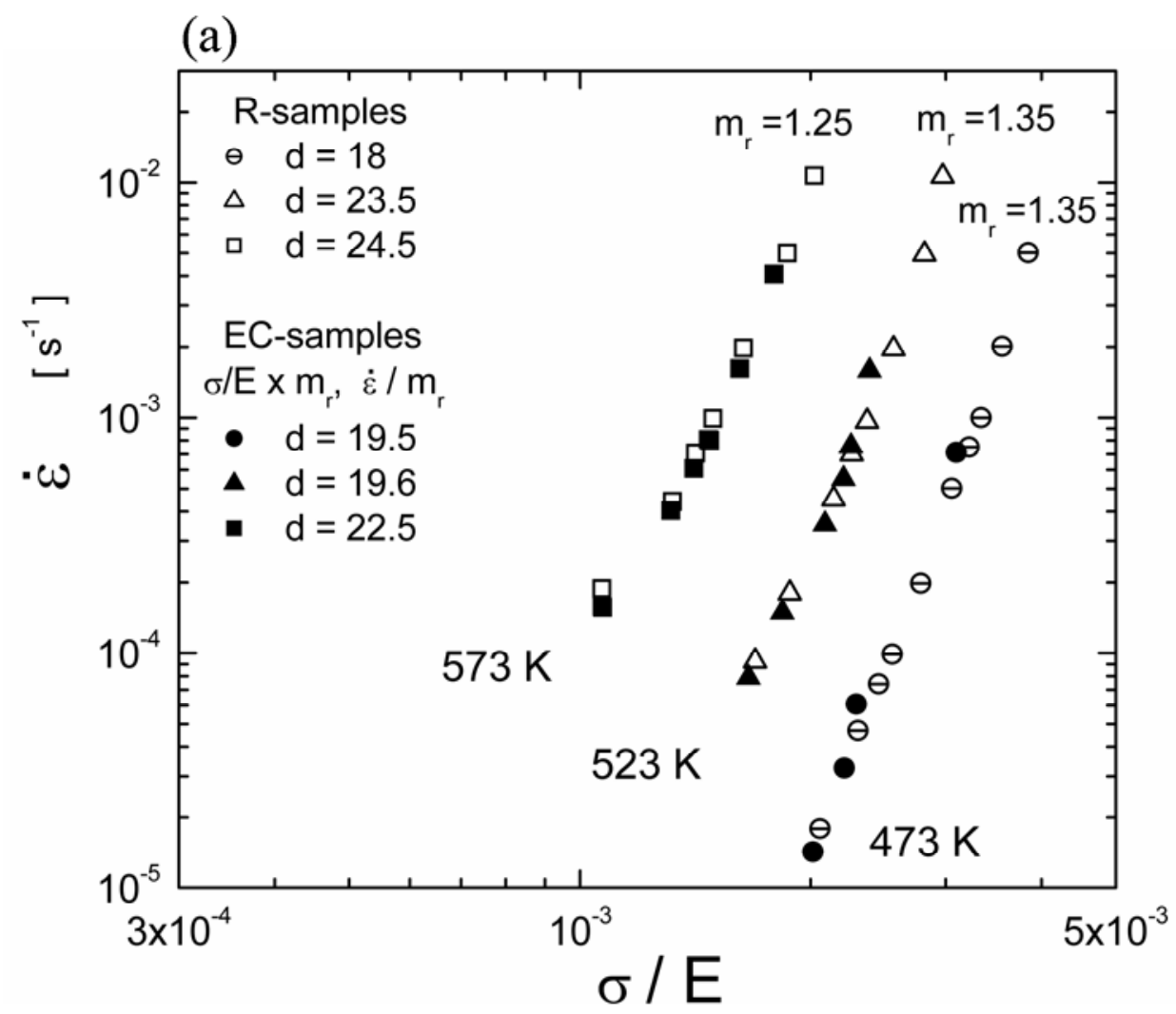

(b)

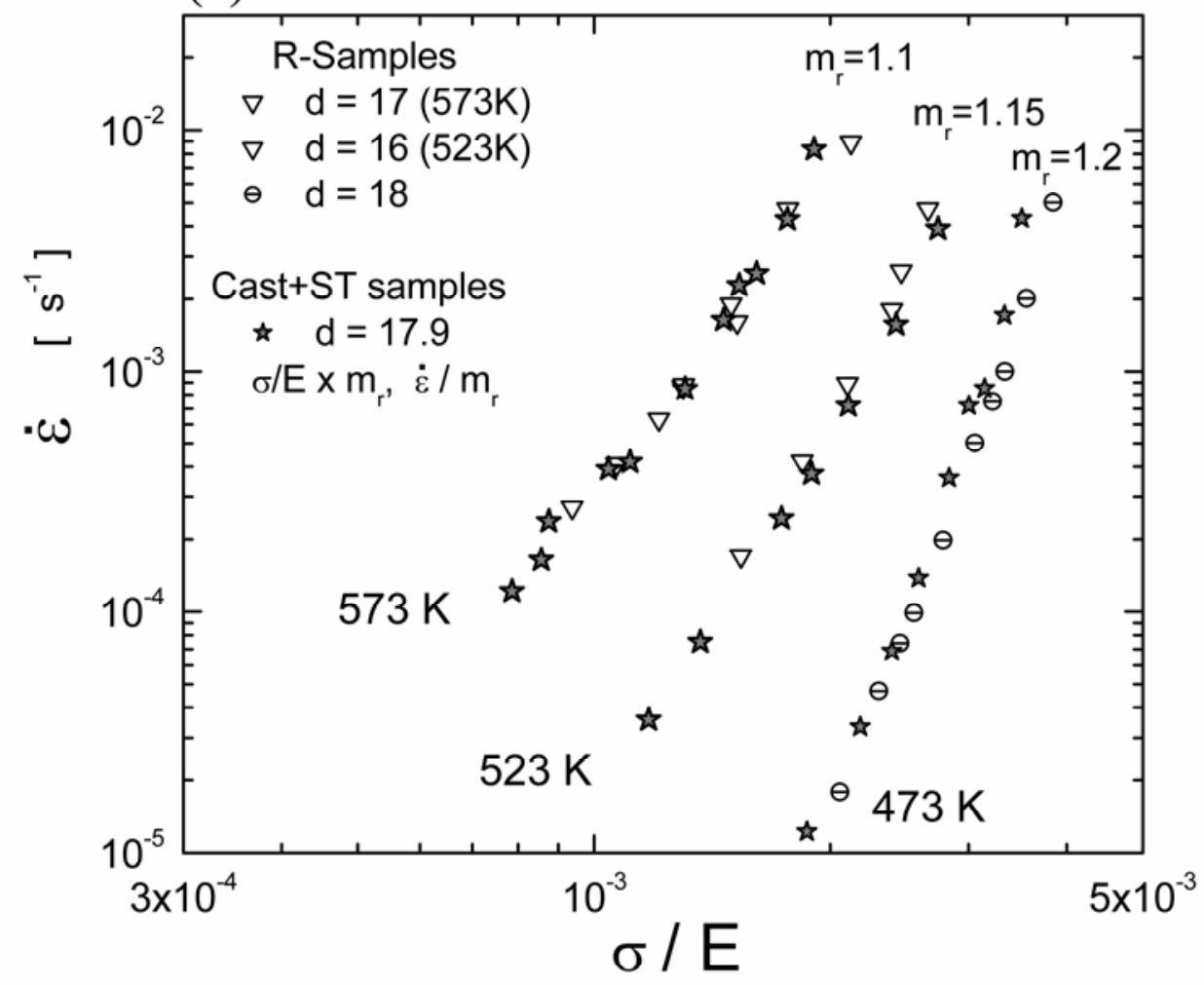

Fig. 11. Comparison of data, with different textures, obtained by various processing routes using the conversion factor $\mathrm{m}_{\mathrm{r}}$. (a) R and EC data; (b) Cast+ST and EC data. 


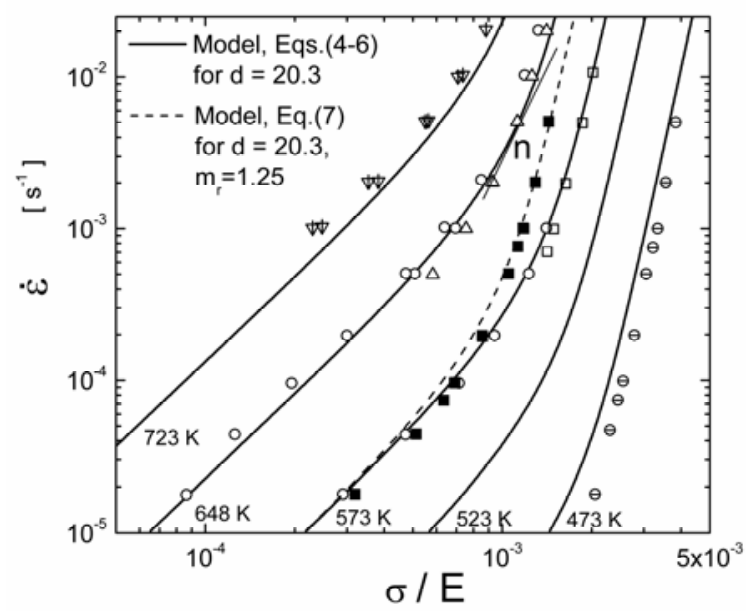

Fig 12. Comparison of the modelled creep behavior, using Eqs.(4-7), against our experimental results for a grain size of $20.3 \mu \mathrm{m}$. The symbols of the experimental data correspond to those of Fig. 6.
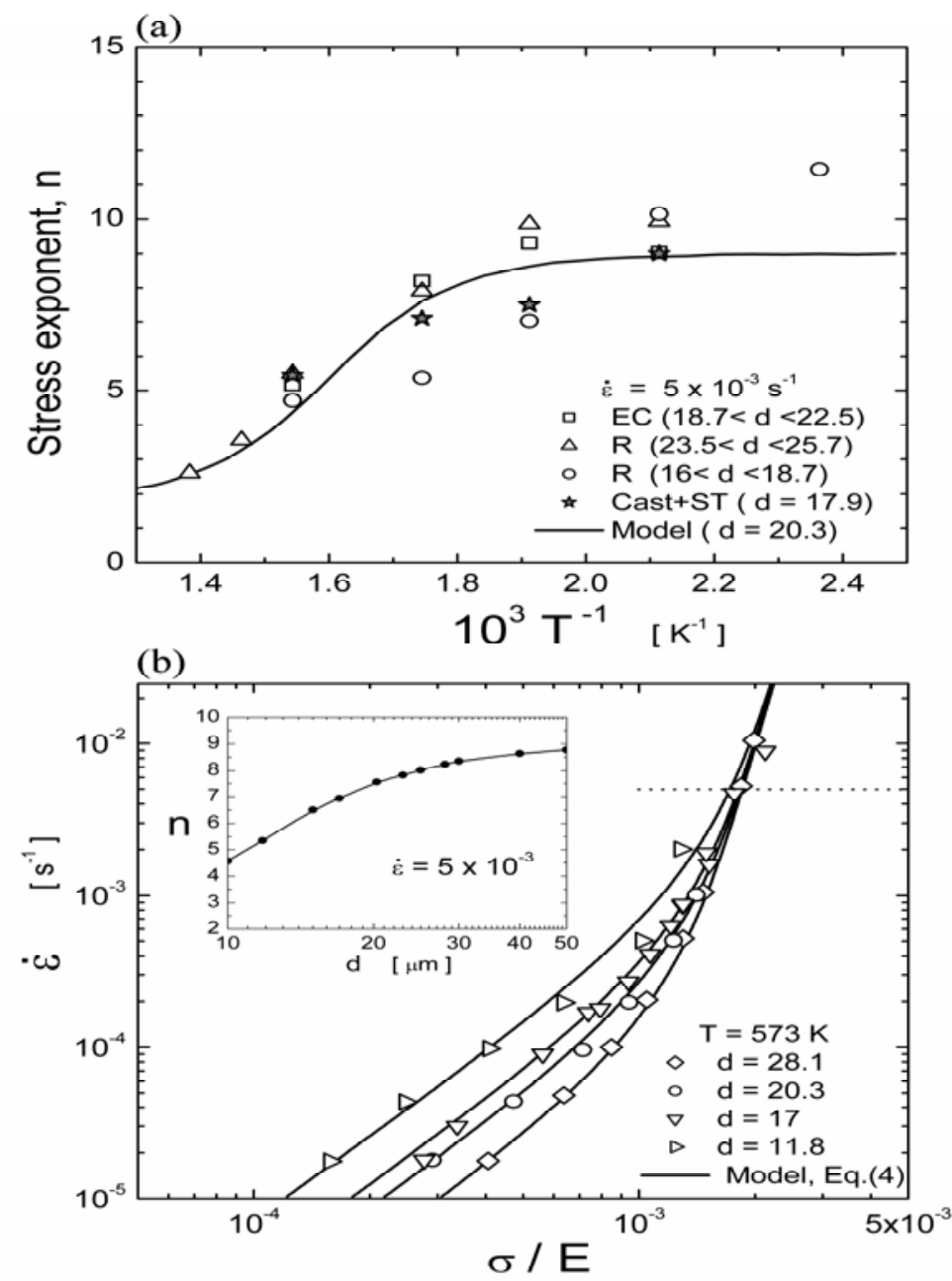

Fig 13. (a) The stress exponent against $\mathrm{T}^{-1}$; the continuous line corresponds to the results obtained with the model given by Eq.(4) for $d=20.3 \mu \mathrm{m}$. (b) The strain rate against $\sigma / \mathrm{E}$ at various grain sizes; the continuous lines are predictions of Eq.(4). The insert corresponds to the dependence of the stress exponent on grain size at $\dot{\varepsilon}=5 \times 10^{-3} \mathrm{~s}^{-1}$. Grain sizes are given in microns. 


\section{References}

[1] Matsubara K, Miyahara Y, Horita Z, Langdon TG. Acta Mater 2003; 51: 3073.

[2] Mabuchi M, Ameyama K, Iwasaki H, Higashi K. Acta Mater 1999; 47: 2047.

[3] Kim WJ, An CW, Kim YS, Hong SI. Scripta Mater 2002; 47: 39.

[4] Pérez-Prado MT, del Valle JA, Ruano OA. Mat Sci Forum 2004; 447-448: 221.

[5] Ruano OA, Sherby OD. Revue Phys Appl 1988; 23: 625.

[6] Ruano OA, Miller AK, Sherby OD. Mat Sci Eng 1981; 51: 9.

[7] Padmanabhan KA, Lücke K. Z Metallk 1986; 77: 765.

[8] Hsu S, Edwards GR, Sherby OD. Acta Metall 1983; 31: 763.

[9] Kaibyshev OA, Kazachkov IV, Salikhov SY. Acta Metall 1978; 26: 1887.

[10] Kaibyshev OA, Rodionov BV, Valiev RZ. Acta Metall 1978; 26: 1877.

[11] Kaibyshev OA, Kazachkov IV, Alexandrov IV. Acta Metall 1984; 32: 585.

[12] Kaibyshev OA, Kazachkov IV, Galeev RM. J Mater Sci 1981; 16: 2501.

[13] Paton NE, Hamilton CH. Metall Trans 1979; 10A: 241.

[14] Garde AM, Chung HM, Kassner TF. Acta Metall 1978; 26: 153.

[15] Watanabe H, Takara A, Somekawa H, Mukai T, Higashi K. Scripta Mater 2005; 52: 449.

[16] Edwards GR, McNelley TR, Sherby OD. Scripta Metall 1974; 8: 475.

[17] del Valle JA, Perez-Prado MT, Ruano OA. Metall Mater Trans 2005; 36A: 1427.

[18] Perez-Prado MT, del Valle JA, Contreras JM, Ruano OA. Scripta Mater 2004; 50: 661.

[19] del Valle JA, Pérez-Prado MT, Ruano OA. Mat Sci Eng 2003; A355: 68.

[20] del Valle JA, Carreño F, Ruano OA, Acta Mater 2006; 54: 4247.

[21] Saltikov SA. Stereology. New York: Springer-Verlag New York Inc; 1967. p. 163.

[22] Vander Voort GF, Metallography, principles and practice. New York: McGraw-Hill; 1984. p. 410.

[23] Tan JC, Tan MJ. Mat Sci Eng 2003; A339: 124.

[24] Randle V, Engler O. Texture Analysis. Gordon and Breach; 2000.

[25] del Valle JA, Perez-Prado MT, Ruano OA. Revista de Metalurgia 2002; 38: 353.

[26] Eddahbi M, del Valle JA, Perez-Prado MT, Ruano OA. Mat Sci Eng 2005; A410: 308.

[27] Kim WJ, Chung SW, Chung CS, Kum D. Acta Mater 2001; 49: 3337.

[28] Watanabe H, Mukai T, Kohzu M, Tanabe S, Higashi K. Acta Mater 1999; 47: 3753.

[29] Duong K, Mohamed FA. Acta Mater 1998; 46: 4571.

[30] Kumar P, Xu C, Langdon TG, Mat Sci Eng 2005; A410: 447.

[31] Kim JS, Kim JH, Lee YT, Park CG, Lee CS. Mat Sci Eng 1999; A263: 272.

[32] Ghosh AK, Raj R. Acta Metall 1981; 29: 607.

[33] Barnett MR, Keshavarz Z, Beer AG, Atwell D. Acta Mater 2004; 52: 5093. 